\section{PL.49 REDUCING THE CAESAREAN SECTION (CS) RATE IN A RURAL HOSPITAL IN SOUTH-WEST UGANDA}

doi:10.1136/archdischild-2013-303966.231

R lon, H Allatt. Royal Berkshire Hospital, Reading, UK

Background The fertility rate in Uganda is $6.1{ }^{1}$ The significance of repeated CS and the risks of labour after caesarean section are well-documented. Often CS is the most appropriate mode of delivery but the decision to operate should be made judiciously to reduce maternal morbidity and mortality.

The CS rate in Kisizii Hospital, previously around 23\% (20092010), had increased steadily to $41 \%$ in July 2012. Retrospective case note examination indicated frequent poor decision-making in labour leading to unnecessary CS. Decisions were often made by very junior staff.

Method The following were implemented in early August:

1. Tutorials on diagnosing \& managing progress in labour and fetal distress

2. Tutorials on vacuum deliveries

3. Algorithms to aid decision-making processes

4. Updated induction of labour guidelines

\section{Results}

\section{Abstract PL.49 Table 1}

\begin{tabular}{lccccccccc}
\hline & Feb & Mar & Apr & May & Jun & Jul & Aug & Sep & Oct \\
\hline $\begin{array}{l}\text { CS rate } \\
\text { (\% del) }\end{array}$ & 39.4 & 41.8 & 33.5 & 34.0 & 36.0 & 41.1 & 26.2 & 23.5 & 31.5 \\
Fresh SB rate $^{*}$ & 1.1 & 1.6 & 2.1 & 2.8 & 0.5 & 2.1 & 2.7 & 2.3 & 2.7 \\
Birth asphyxia rate* $^{*}$ & 0.6 & 5.4 & 1.0 & 14.9 & 6.3 & 1.1 & 2.0 & 5.1 & 3.4 \\
\hline
\end{tabular}

*percentage of live births

The CS rate for August to October was statistically significantly less than for January to July ( $p<0.05$, Fisher's exact test). There were no significant differences observed in the fresh stillbirth or birth asphyxia rates.

Conclusion Simple algorithms with timely tutorials can help junior staff to improve their decision-making processes where the preferable alternative of continual senior support is not feasible.

\section{PL.50 AN AUDIT EXPLORING THE IMPACT OF NICE CAESAREAN SECTION GUIDANCE ON ELECTIVE CAESAREAN SECTION RATES AT THE COUNTESS OF CHESTER HOSPITAL (COCH)}

doi:10.1136/archdischild-2013-303966.232

2J Gent, 'S Brigham. 'Countess of Chester Hospital, Chester, UK; '2University of Liverpool, Liverpool, UK

Background In November 2011, NICE released new guidance for Caesarean Sections in the UK. The new guidance stated that "for women requesting a CS, if after discussion and offer of support, a vaginal birth is still not an acceptable option, offer a planned CS"1. This audit will look into whether this has increased CS rates at $\mathrm{COCH}$.

Method 40 sets of patients notes were selected to represent a snapshot of elective CS from January $1^{\text {st }} 2012$ to June 30 ${ }^{\text {th }}$ 2012. Data collected included documented indication for delivery, actual indication for delivery as well as elective CS rates for 2010, 2011 and 2012

Results The overall elective CS rate for the hospital increased by $2 \%$ between Jan-June 2011 and 2012 compared to only a 1\% rise between 2009-2011. The overall maternal request rate has increased from $0.5 \%$ of total deliveries in 2010 and 2011 to $1.4 \%$ in Jan- September 2012. Within the cohort the maternal request rate was $7.5 \%$ for Jan to

${ }^{1}$ UNICEF 2010
June 2012 compared to $5.5 \%$ in 2010. There was a large disparity between documented and actual indication for delivery of 30\%.

Conclusion From the results of this audit we can see that elective CS rates due to maternal request are on the increase. This suggests that the NICE guidance released in November 2011 has had an impact, to what degree is difficult to say however we can better substantiate this with annual figures.

\section{REFERENCE}

1. NICE. CG132 Caesarean section: full guideline. 23 November 2011 [Online]: Available from: http://guidance.nice.org.uk/CG132/Guidance/pdf/English

\section{PL.51 SEVEN IN ONE YEAR: LESSONS LEARNED FROM A REVIEW OF PERIPARTUM HYSTERECTOMY IN A DISTRICT GENERAL HOSPITAL}

doi:10.1136/archdischild-2013-303966.233

M Latibeaudiere, I Babarinsa. Gloucestershire Hospitals NHS Foundation Trust, Gloucester, UK

Following an unusual number of peripartum hysterectomies performed in the calendar year August 2011 to August 2012 in our district general hospital, we undertook a detailed review of the seven cases in which caesarean hysterectomies were necessitated by major obstetric haemorrhage, an incidence of about 12 per 10,000 deliveries, approximately three times the incidence quoted in UKOSS data.

Comparing these with the available national data regarding pathophysiology, we noted that the higher than expected incidence of placental implantation abnormalities were likely the causative factor (4 of 7 (57\%) cases reviewed compared to 39\% in national evidence). Evidence of good clinical practise was noted with respect to consent, appropriate staffing and involvement of senior clinicians. A range of measures were used prior to hysterectomy, including pharmacological treatments, haematological correction of coagulopathy, haemostatic brace sutures and uterine compression balloons.

While it is hoped that the number of cases represents a statistical 'blip' rather than an on-going trend, our experience emphasises the challenges faced by a busy district general hospital dealing with rising birth rates and increasing case complexity. We discuss the lessons learned from this case review, including the role of clinical governance and the benefit of open professional discussion.

\section{REFERENCES}

1. Knight $\mathrm{M}$ on behalf of UKOSS. Peripartum hysterectomy in the UK: management and outcomes of the associated haemorrhage. BJOG 2007;114:1380-1387.

2. Prevention and management of postpartum haemorrhage. RCOG Green Top Guideline No. 52. May 2009. RCOG.

3. Placenta praevia, placenta praevia accrete and vasa praevia: diagnosis and management. RCOG Green Top Guideline No 27. RCOG 2011.

\section{PL.52 PLACENTA ACRETA IN ST VINCENTS UNIVERSITY HOSPITAL 2008-2011}

doi:10.1136/archdischild-2013-303966.234

S Elsayed, G Ryan, P Lenehan. St. Vincent University Hospital, Dublin, Ireland

This is a retrospective review of all the patients who had a caesarean section for suspected placenta acreta in St Vincent's Hospital (SVH) from December 2008 to October 2011.

The study includes all women who were referred to SVH for caesarean section with an antenatal diagnosis of placenta acreta/percreta. The review included patient's age, parity and previous caesarean sections, antenatal diagnosis with ultrasound and MRI, hysterectomies performed, conservative management, ICU/HDU admissions after the procedure and radiological input. The review excludes women who had caesarean sections in SVH for other indications.

Results During the period 11 women had caesareans sections in $\mathrm{SVH}, 6$ of these women had a caesarean section for suspected 